Landscapes: Translation of

identity.

Project TRAMA AZUL. New approaches and visions for sustainable development of the Territory and Landscape

\section{| RESUMEN |}

Se presenta una propuesta Paisajística de planificación y gestión de la cuenca Río Mataquito para la recuperación del Humedal La Pesca. Tomando en cuenta nuevas metodologías para la elaboración de un Plan que recupera el Paisaje e identidad local del lugar, sus principales tradiciones y culturas propias del entorno, constituyendo nuevos enfoques de acción sobre el territorio que hoy quedan obsoletos en los actuales Instrumentos de Planificación usados en Chile.

\section{| ABSTRACT |}

This project is a proposal for Landscape Planning and management of the Mataquito River for the recovery of La Pesca wetland. It takes into account new methodologies for the elaboration of a plan to recover the landscape and the local identity of the place, its main traditions and own cultures, establishing new approaches to action on the territory, considering that the current planning instruments used in Chile are obsolete.

ISIDORA THOMAS R.*

\title{
Paisajes: Traducciones de identidad Proyecto TRAMA AZUL. Nuevos enfoques y miradas para el desarrollo sustentable del Territorio y sus Paisajes
}

\section{INTRODUCCIÓN}

Chile se caracteriza principalmente por la variedad de sus paisajes y por la fragilidad con que estos cambian, ya sea por impactos de la naturaleza o impactos antrópicos, incidiendo en el desarrollo social, económico y ambiental del territorio. Siempre existirán estos cambios y mutaciones en el espacio físico a lo largo del tiempo y es por esto que es indispensable contar con herramientas que regulen o más bien planteen lineamientos y estrategias de largo plazo para el devenir de nuestro Territorio.

Las actuales problemáticas que afectan al país tienen raíz en la ausencia de políticas públicas competentes en el ámbito del desarrollo territorial, permitiendo que las actuales economías y el crecimiento del país decidan sin ninguna estrategia común la evolución del territorio. Una condición que afecta principalmente a lugares de características complejas, a su naturaleza y cultura, deformados por manejos disciplinares que no logran capturar su esencia más pura. Los principales dilemas se relacionan con el medio ambiente, tales como la escasez del agua, la contaminación de ciudades, la desaparición de la agricultura local, la afección de especies endémicas y ecosistemas únicos, problemáticas temas que comienzan a estar cada vez más en voga.

En este contexto, surge una inmensa necesidad de replantearse el desarrollo del país, entender cuál es nuestra identidad más propia y lograr que permanezca en el tiempo, adaptándose a transiciones y transferencias de los manejos que se usan a nivel mundial para la conservación y recuperación de paisajes culturales, propiciando un desarrollo sustentable del territorio en diferentes escalas de acción.

En una escala local podríamos decir que la Arquitectura del Paisaje juega un rol indispensable para el territorio encargándose de unir la materia sólida con el espíritu, la memoria viviente portada por el hombre, planteando una aproximación territorialista (Mangiaghi, 2003) con respecto a los lugares. Da el espacio para descubrir, en conjunto, los nuevos usos del territorio los cuales no son la negación de sus precedentes, sino todo lo contrario, encontrar las medidas y la visión con que se enfrentan las nuevas y antiguas prácticas en donde la sensibilidad e integración conducirán el habitar y el paisaje. 
1. Cuenca del Mataquito.

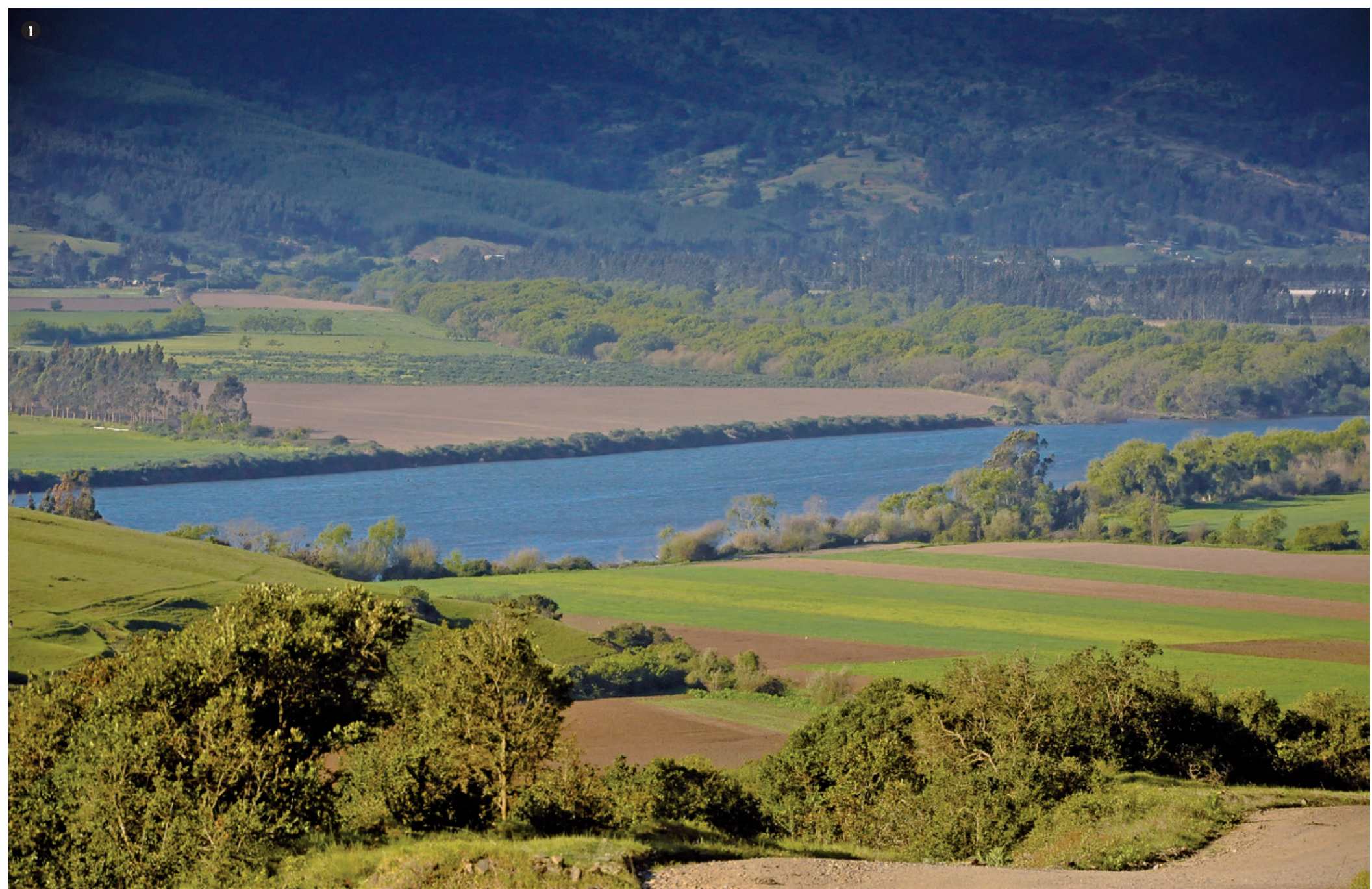

\section{ORDENAMIENTO TERRITORIAL EN CHILE}

Hoy en nuestro país no existe una política de planificación territorial efectiva, capaz de potenciar los recursos naturales para el desarrollo de una economía local compatible con el medio ambiente, la cultura y el paisaje. Una situación que deja a la deriva a los territorios rurales, pues hoy en día no se rigen bajo ningún marco legal normativo. En algunos casos los Planes Reguladores Intercomunales intentan planificar y establecer estrategias de desarrollo en dichos territorios, pero queda siempre la posibilidad de aplicar el art. №55 de la Ley General de Urbanismo y Construcción que permite el cambio de uso de suelo en áreas fuera del límite urbano. Justamente es en las zonas rurales donde nos encontramos con lugares de esencias complejas de alta fragilidad, compuestos por paisajes únicos e irrepetibles.

Bajo estas condiciones, el Reglamento de Evaluación Ambiental Estratégica (EAE) constituye una nueva oportunidad para cambiar la actual visión de los instrumentos utilizados en Chile. Planteando una visión estratégica en base a decisiones políticas más que a decisiones tecnisistas, este documento pone sobre la mesa una discusión en torno a cuáles son las políticas necesarias para el ámbito territorial, considerando por ejemplo temas vinculados con los recursos naturales o la generación de energía, temáticas que deben ser incorporadas en una planificación sectorial y tangible.

\section{BASES DE UNA APROXIMACIÓN TERRITORIALISTA}

Una aproximación territorialista apuesta por sistemas configuradores de la relaciones generadas entre el hombre y su medio, construyendo un paisaje identitario y una estructura que perdure más allá de las transformaciones que conlleva el paso del tiempo. 

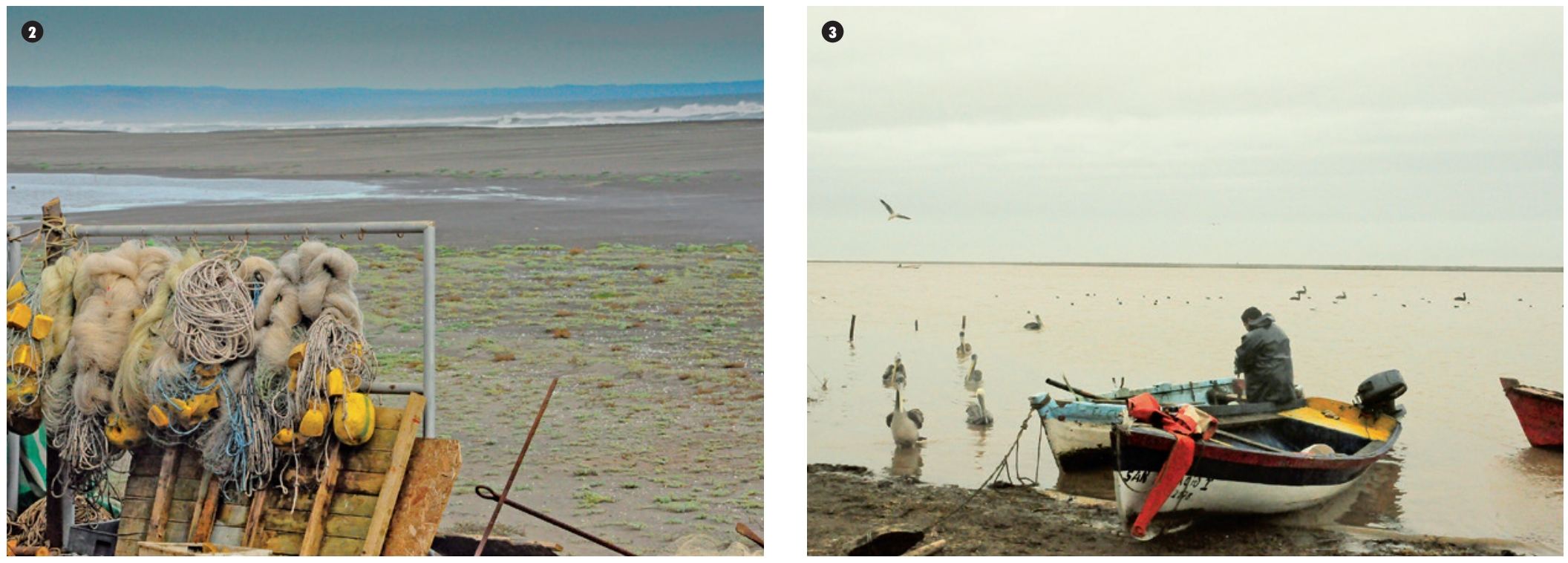

\section{BIODIVERSIDAD-ECOSISTEMA}

Los fenómenos del ecosistema que ocurren en diferente escalas de tiempo en el territorio, son la base de una cadena de "relaciones virtuosas" en el territorio. Contemplar la data que nos entrega el ecosistema permite un planeamiento sostenible territorializante, entendiendo la relación de cada comunidad con el espacio y el desarrollo de identidad.

\section{SOCIODIVERSIDAD-IDENTIDAD COLECTIVA}

El sentido de pertenencia grupal se forma a partir del tejido relacional con la naturaleza local, dando paso a un elemento cohesionador principal, que opera como fuente de elementos cohesionadores secundarios (valores, hitos, tradiciones, espacios sociales/culturales, actividades). La trama de rituales cotidianos genera interacciones en cada cultura local, portadoras de "conocimientos" y prácticas que formalizan tipos de permanencia de cada lugar, de esta manera se construyen las memorias vivientes asociadas a las experiencias, valores culturales y espacios sociales, los cuales generan un sentido común que contiene identidad, diferenciándose del mundo externo, creando un paisaje único, un paisaje cultural.

\section{COSMOVISION-MEDIO HUMANO}

Los objetivos de planeamiento van dictando las estrategias de acción en el territorio, las cuales deben apuntar-siguiendo la concordancia de relaciones virtuosas que hemos señalado precedentemente- al paisaje con respecto a un desarrollo sostenible del espacio en el tiempo. En este sentido es fundamental el desarrollo de políticas descentralizadas que se generen desde el lugar y no desde afuera hacia el lugar, potenciando el desarrollo autónomo local, dando la oportunidad de incorporar al planeamiento del territorio la comunidad gestora del paisaje.

\section{PROYECTO TRAMA AZUL, UNA PROPUESTA PARA LA TRANSFERENCIA E INCORPORACIÓN DE NUEVOS ENFOQUES Y MIRADAS EN EL ORDENAMIENTO TERRITORIAL EN CHILE}

TRAMA AZUL es un Plan de Recuperación de ecosistemas acuáticos de la región del Maule, planteando el Ordenamiento del Territorio para el Desarrollo Local del Humedal de La Pesca/Río Mataquito, revalorizando el borde costero a través de la reconstitución de servicios ecológicos y del paisaje.
El plan considera la extensión de dos comunas, Curepto y Licantén, las cuales están separadas por la gran cuenca del río Mataquito que desemboca en la planicie costera de la localidad La Pesca, conformando un humedal de aguas mixtas con gran valor ecológico.

La localidad de La Pesca es una caleta de pescadores de no más de 80 familias, ubicada en la costa de la comuna de Licantén. Este villorrio forma parte de la ruta de las Caletas del Maule, siendo la puerta de entrada de la ruta. La actividad de las caletas tiene un doble propósito, por una parte, se dedican a la pesca deportiva y, por otra parte, a la pesca artesanal de diversas especies, siendo la localidad de La Pesca la única de este borde costero que desarrolla la pesca artesanal a remo en aguas "dulces" en el humedal.

\section{DIAGNÓSTICO DEL TERRITORIO}

El diagnóstico del territorio se lleva a cabo bajo una metodología basada en el enfoque territorialista a partir de tres sistemas relacionales: biodiversidad - ecosistema, sociodiversidad - identidad colectiva y cosmovisión - medio humano. 
(4)

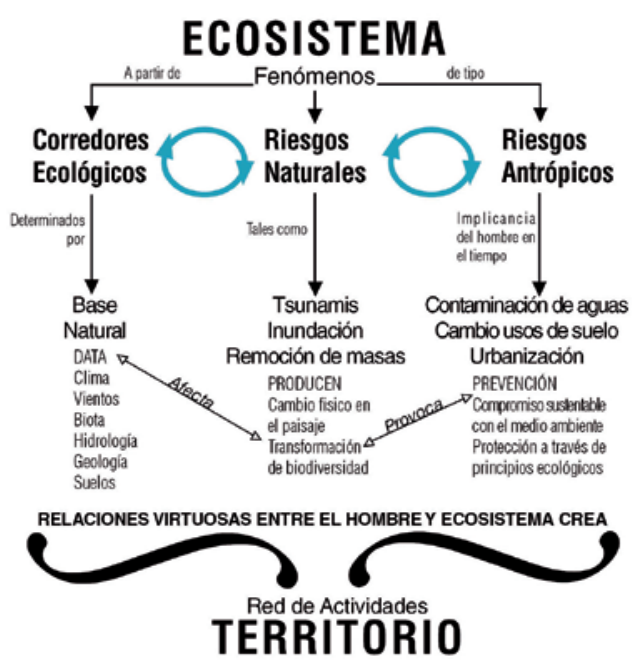

La investigación y construcción de la propuesta se realizó en base a descripciones espaciales, conversaciones y entrevistas con los habitantes, visitas a la Municipalidad y recorridos por el territorio, con el propósito de determinar el estado actual del territorio, sus principales problemas y necesidades. En definitiva, un encuentro empírico con la materialidad de los componentes de la naturaleza que determinan relaciones virtuosas o no virtuosas en el territorio local de La Pesca.

\section{RELACIONES VIRTUOSAS}

- En los bordes del río Mataquito presencia de tierras para uso agro-ganadero, de bajo porcentaje de ocupación, por lo que no afecta las aguas del río con residuos. Además, se utiliza sistema de regadío a partir de aguas del río.

- Punto de encuentro de pescadores a borde del humedal para salir a tirar redes. Lugar de trabajo sin ninguna infraestructura, no impacta el ecosistema del humedal, su relación con este es adecuada y genera un sentido de protección y cuidado.

- Roca de San Pedro, lugar de encuentro para la comunidad, y donde se hacen todas las celebraciones de los pescadores y se le rinden honores a San Pedro. Esto demuestra
(5)

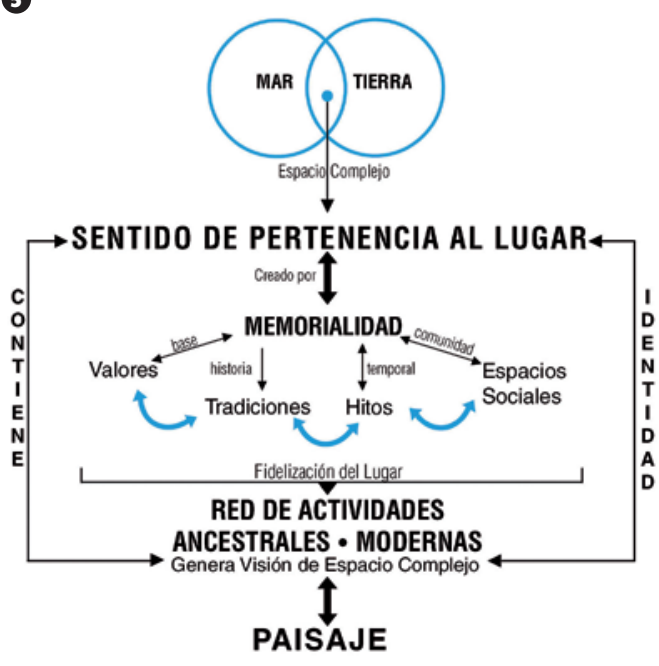

un sentido de pertenencia de la comunidad para con su medio.

- Los habitantes encuentran un refugio en la morfología del cerro emplazándose en desnivel de cotas, esto genera una relación virtuosa con respecto al mar, ya que se obtiene una altura entre 20 y 45 msnm, otorgando una visión panorámica del territorio y una forma de mitigación contra tsunamis.

\section{RELACIONES NO VIRTUOSAS}

- Cotas, forestadas por privados, en Cordillera de la Costa, suelos con posibilidades de erosión a un futuro por proceso de desforestación.

- Planta de celulosa Licantén ubicada en el sector, no fue controlada por gobiernos locales, por lo que arrojó residuos nocivos a aguas del río Mataquito. Hoy en día se ha controlado la contaminación y el río y humedal han comenzado una restitución natural de sus aguas. Sin embargo, es necesaria una intervención de restitución artificial para volver a niveles de biodiversidad.

- Cambio usos de suelo en borde inmediato del humedal por parte de los propietarios de las tierras, cambiando la condición natural
(6

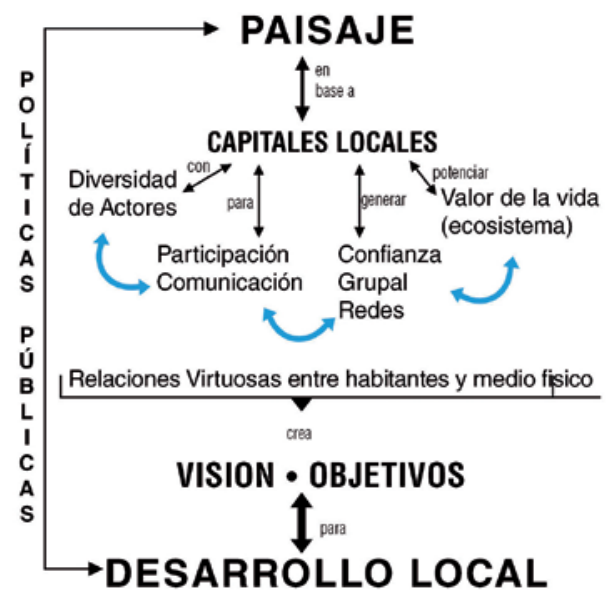

del borde y del ecosistema, incorporando gaviones de protección, rejas de separación con alambre de púa que afecta a la avifauna. Además, del uso de pesticidas y químicos tóxicos para la producción agrícola, que afecta las aguas del humedal.

- Ruta J-60 conectora de borde costero con Licantén y Curicó, responde a su funcionalidad, generando una vía de comunicación rápida, pero su emplazamiento es muy próximo al humedal y praderas naturales, causando un impacto en la biota, su existencia conlleva al desplazamiento de especies, contaminación acústica, accidentes, modificación de biotopos, impermeabilización de suelos. Además, pasa por el centro del poblado y no tiene vereda peatonal.

- Suelos erosionado en piedemonte (Cordillera de la Costa) continuo al humedal debido a la tala a ras de bosques de pinos, produce una escorrentía muy alta arrastrando aguas contaminadas y con muchos sedimentos al humedal.

\section{CARACTERIZACIÓN DEL ESPACIO A TRAVÉS DE RELATOS DE HABITANTES}

"Era más lindo aquí antes, habían más árboles se sentía mucho más la naturaleza y el humedal 
8. Santuario de la Naturaleza Humedal La Pesca.

\section{(}

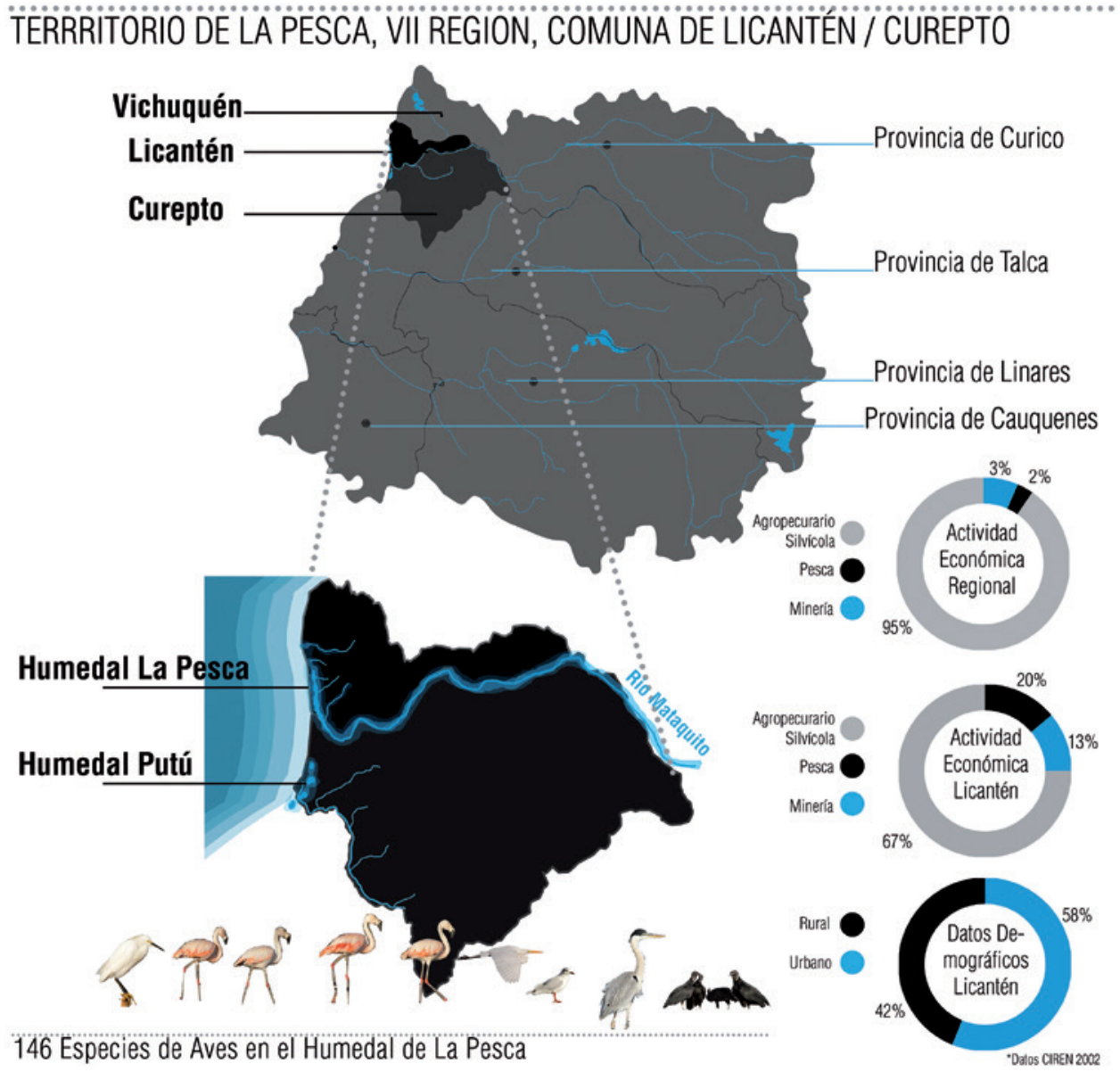

daba en abundancia, machas, pescados, de todo y ya no es así. Antes en el cerro se cosechaba trigo, papas. Estaban los prados sembrados y ya se perdió la agricultura". Rosa Valenzuela - Relatos de La pesca

"Era lindo cuando el río (humedal) llegaba hasta acá mismo, yo miraba por la ventana y se veía, en cambio ahora es triste ver este vacío de playa así que yo lo extraño". Nora Gutiérrez - Relatos de La Pesca

"Aquí nos diferenciamos por pescar en el humedal, tenemos botes más pequeños en comparación con lloca y Duao, eso nos hace tener nuestras propias técnicas de pesca artesanal". Pescador no dio su nombre - Relatos de La Pesca.

"Yo que me la paso en el río (humedal) conozco bien, no como las dueñas de casa, yo me he dado cuenta de los cambios que tiene. Antes tenía un pastizal bien alto, que ahora ya no tiene, era como una totora gruesa. Yo creo que por eso se han ido algunos de los pájaros, ya no hay patos, ni el pitroco, ni las taguas. Por eso así como vamos, yo me imagino con muy poca esperanza el futuro de La Pesca, porque ya no existe la reproducción de los animalitos que había antes, ahora van decayendo". Elsa Relatos de La Pesca,

\section{PROPUESTA}

La propuesta se basa en la recuperación del humedal de La Pesca a través de la rehabilitación de los principales corredores ecológicos del territorio, para potenciar el beneficio de los servicios ecológicos que nos entrega la estructura hídrica del paisaje. De esta manera, se genera una valorización de la cultura local gestada en el medio físico en torno al humedal.

\section{El territorio propuesto presenta una} fragmentación espacial y una pérdida de la riqueza natural del paisaje, quitándole dramatismo a su belleza y dándole la espalda a su eje configurador: el agua. 
9. Diseño Propuesta del Plan.

9

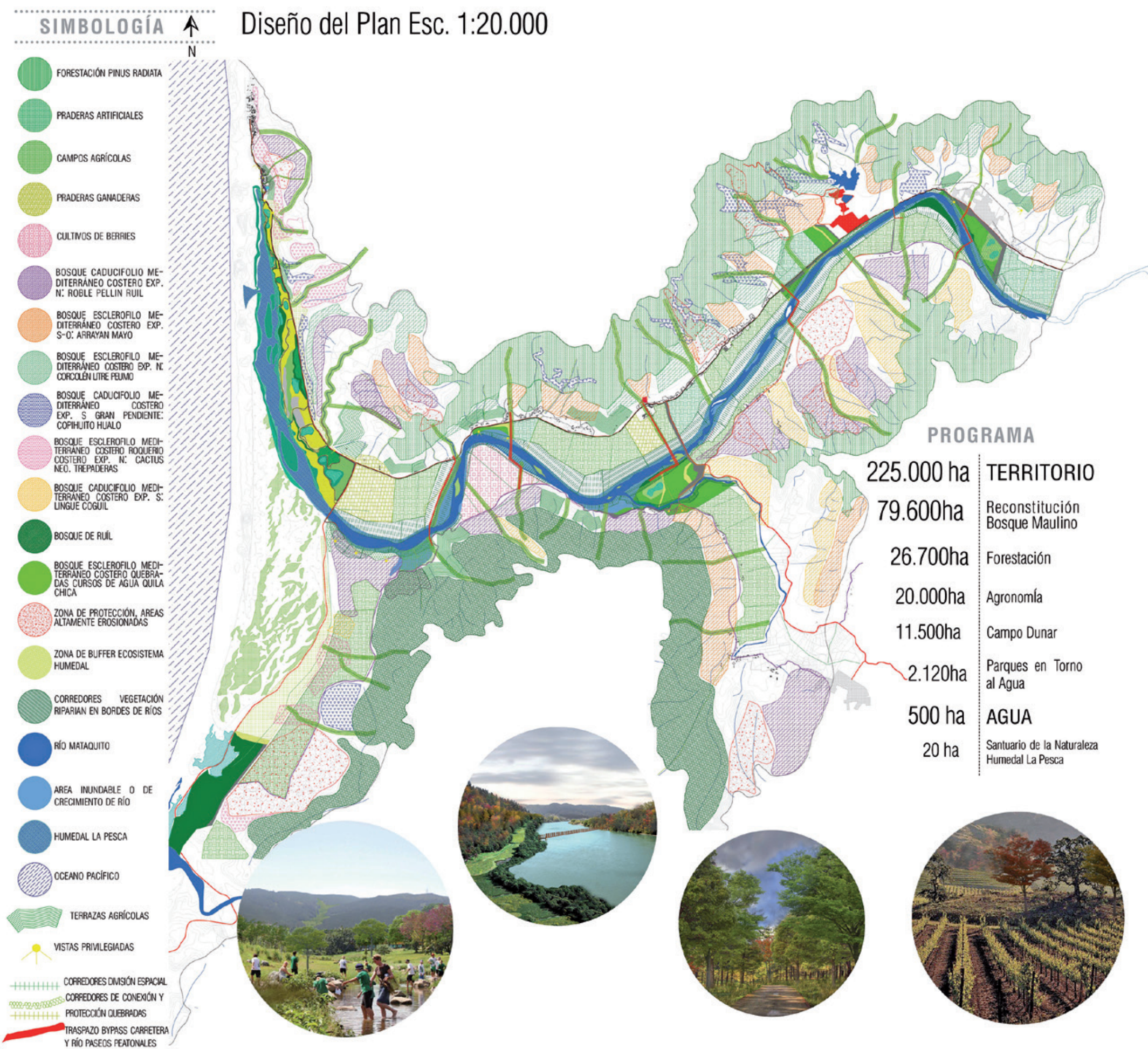


La estrategia para enfrentar la recuperación del paisaje fluvial es gestar el plan de ordenamiento del territorio en torno a LA TRAMA AZUL, restaurando los cursos de agua, haciendo sus capas históricas más visibles en cuanto a la vegetación, antiguas actividades, economías locales y sobre todo El Paisaje, poniendo a los actores locales como cabeza de la transformación, enriqueciendo sus recursos y redes para encontrarles nuevas finalidades que perduren en el tiempo.

El Plan trabaja en distintas escalas, revelando diversos aspectos para el devenir del territorio, el cual tiene un futuro crítico, de extremo deterioro -casi irreversible- si no se interviene y reconstituye. La riqueza paisajística se da por sus elementos típicos y claros, los cursos de agua: río Mataquito, quebradas, pequeños esteros, mar y el humedal que son acompañados por unidades paisajísticas de grandes extensiones: campos agrícolas, praderas, campo dunar, planicie litoral, bosques autóctonos y forestación. Estas unidades han ido cambiando su estructura con el pasar de los años y los porcentajes de ocupación de suelos han valorizado la economía privada antes que potenciamiento local del paisaje. La cantidad de forestación ha crecido sustancialmente, por lo que el contraste de las unidades paisajísticas, que generaban un equilibrio visual de áreas abiertas y cerradas, se ha debilitado, determinando la extinción de vegetación autóctona y deteriorando los suelos.

El diseño del Plan trae de vuelta la estructura y la belleza del paisaje, incentivando el contraste entre grandes matrices del paisaje y su núcleo estructurador, el agua. Una recombinación de las unidades existentes de mejor manera para un futuro sostenible y con gran potencial ecológico.

\section{ESTRUCTURA DEL PLAN}

En torno a la TRAMA AZUL se prioriza el río Mataquito y el humedal de La Pesca como eje configurador, a partir del cual nacen ramificaciones de corredores que extienden "brazos" hacia la extensión del territorio, principalmente hacia la Cordillera de la Costa, generando un flujo natural y un nuevo ambiente de traspaso ecosistémico. Nuevos núcleos verdes vienen a contener el gran eje de la TRAMA AZUL, los parques esponjas en los bordes del gran curso de agua, emplazados en zonas estratégicas en unión a los poblados y en lugares de posibles crecidas. Proporcionando un espacio natural en conexión con la naturaleza y la contemplación del paisaje, que también se da en el acceso del territorio desde la carretera, generando vistas y paisajes variantes que dramatizan el viaje por el lugar. Hacia un costado de la ruta se encuentran grandes espacios abiertos que cambian de tonalidades y percepciones según la unidad paisajística establecida (agricultura, praderas, ganadería), cada ciertos momentos se denota el cambio por la irrupción de arboledas lineales que delimitan el espacio. Por el otro costado tenemos la imponente Cordillera de la Costa en donde encontramos una mixtura de colores, texturas y matrices. Grandes unidades de vegetación autóctona interceptadas por quebradas y corredores verdes, que se pierden en la altura con áreas forestales casi indivisibles a la escala del hombre. Cada cierta distancia la presencia de pequeños poblados, donde podemos encontrar productos locales producidos en su entorno, en terrazas de cultivos o pequeñas industrias locales (lechería, viñedos, colmenas, etc.).

En el borde costero y con la presencia del mar en el paisaje se configura el principal parque esponja del territorio, el "Santuario de la Naturaleza Humedal de La Pesca". Un gran centro ecológico de condiciones totalmente naturales donde se pueden observar una variedad infinita de aves y plantas exóticas, además de la presencia de pequeños botes en una zona de los pescadores de la localidad de La Pesca. En definitiva un paisaje cultural de gran valor donde la contemplación y la recreación son los objetivos principales del espacio.

\section{DETALLE DEL PLAN}

\section{PROTECCIÓN DE ÁREAS ALTAMENTE EROSIONADAS}

Definir zonas en donde la erosión del suelo es drástica, principalmente en el corredor Cordillera de la Costa debido al alto impacto de la forestación de pinos. Se determinan áreas donde no puede haber intervención forestal y se comienza una rehabilitación vegetal en unión a quebradas para el dotamiento de agua.

\section{CORREDORES RIPARIAN}

La vegetación de ribera es un componente clave de los ecosistemas fluviales que proporciona una gran cantidad de Servicios Ecosistémicos. Por un lado, estas formaciones vegetales regulan los flujos de materia y energía en los ecosistemas acuáticos y terrestres, aportando materia orgánica (hojarasca, ramas, frutos, etc.), además por su microclima húmedo, representan un hábitat favorable para muchos anfibios y mamíferos pequeños, y la vegetación en estas zonas juega un papel muy importante.

Se diseña corredor Riparian en torno al río Mataquito con distancias variables con una media de $300 \mathrm{~m}$, distancia que asume también una zona de crecida de aguas.

\section{CORREDORES DE PROTECCIÓN Y CONTINUACIÓN DE QUEBRADAS}

Tras el registro de quebradas existentes, se diseña una estrategia de protección y diseño; en donde todas las quebradas constan con un corredor de vegetación autóctona de protección con la prohibición de plantar especies introducidas (en este caso determinando a la industria de forestación con los pinos). Esta área de protección varía su extensión según el grado de importancia determinado por su pendiente y prolongación. Se estimula a los cursos de agua a reconstituir su curso natural con un flujo continuo y sin interrupciones (carretera). 
10 y 11 . Corte esquemático.

(1)

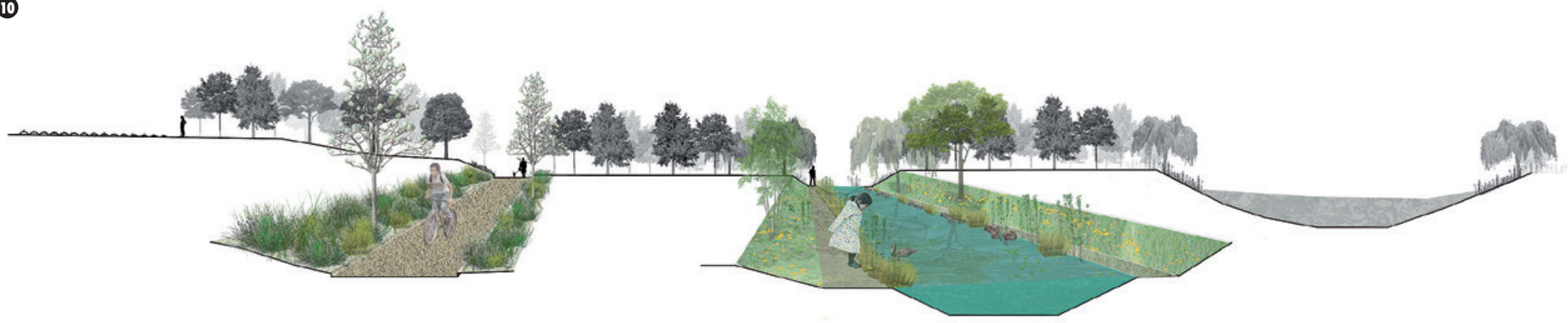

(1)

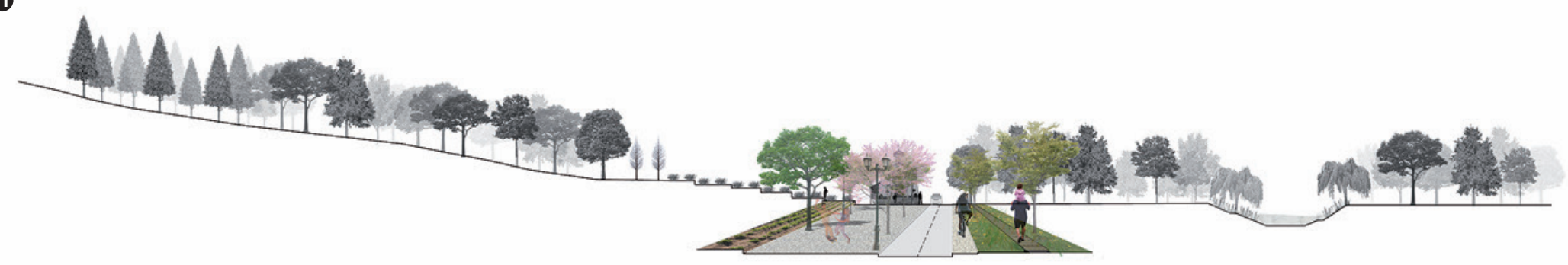

Además, en las prolongaciones de las quebradas que atraviesen por los poblados o sus cercanías, se diseña un ambiente acogedor proporcionando un espacio para el hombre cercano al agua, generando áreas verdes de condiciones naturales, que ayuda a equilibrar el medioambiente y ecosistema, regulando temperaturas, disminuyendo el escurrimiento del agua y aumentando la absorción de la misma.

\section{TERRAZAS DE CULTIVOS}

Secciones de cultivos a nivel local unidos a los poblados, que tienen un valor culturalhistórico, ya que antiguamente se generaba esta condición en los faldeos de la Cordillera de la Costa. En algunos casos pueden estar asociados a la apicultura o viticultura. Las comunidades del lugar trabajaban la tierra para la producción y subsistencia local. Esta actividad sigue sucediendo en algunas zonas, pero se ha ido extinguiendo por la llegada de la forestación en masa que ha cambiado el uso de los suelos en porcentajes extremos. De esta manera se construye una "franja" espacial que permite amortiguar el impacto directo de los poblados con las plantaciones forestales, proporcionando una vista más equilibrada.

\section{GRANDES ÁREAS DE UNIDADES PAISAJISTICAS}

- Agricultura

- Praderas artificiales

- Ganadería

- Forestación

\section{CORREDORES DE ARBOLEDAS DIVISIÓN ESPACIAL}

La secciones de unidades paisajísticas serán complementadas por nuevas líneas de árboles principalmente especies de robles de la zona, ya que son característicos, y en algunos lugares más estratégicos con Ruil, árbol endémico del territorio y en extinción. De esta manera se configuran corredores lineales que permiten un orden espacial y un cambio en la extensión de las unidades, generando cortes visuales incorporando un dramatismo al paisaje y un quiebre a la monotonía.

\section{TRASPASO CARRETERA}

Se diseña dos tipos de traspasos: biótico y antrópico de esta manera se genera una continuidad de corredores y flujos que hasta el momento están siendo interceptados por la carretera J-40, produciendo una división espacial paisajística y una problemática para los habitantes del territorio para lograr una cercanía a los bordes del rio y/o humedal.

El traspaso biótico se produce por el hundimiento del terreno, a través de un bypass por debajo de la carretera asociado especialmente a las quebradas que vienen de la cordillera para que tengan su desagüe en los grandes cursos de agua en acompañamiento de corredores verdes. 
12. Panorámica. Santuario de la Naturaleza Humedal La Pesca

13. Programa Santuario de la Naturaleza Humedal La Pesca

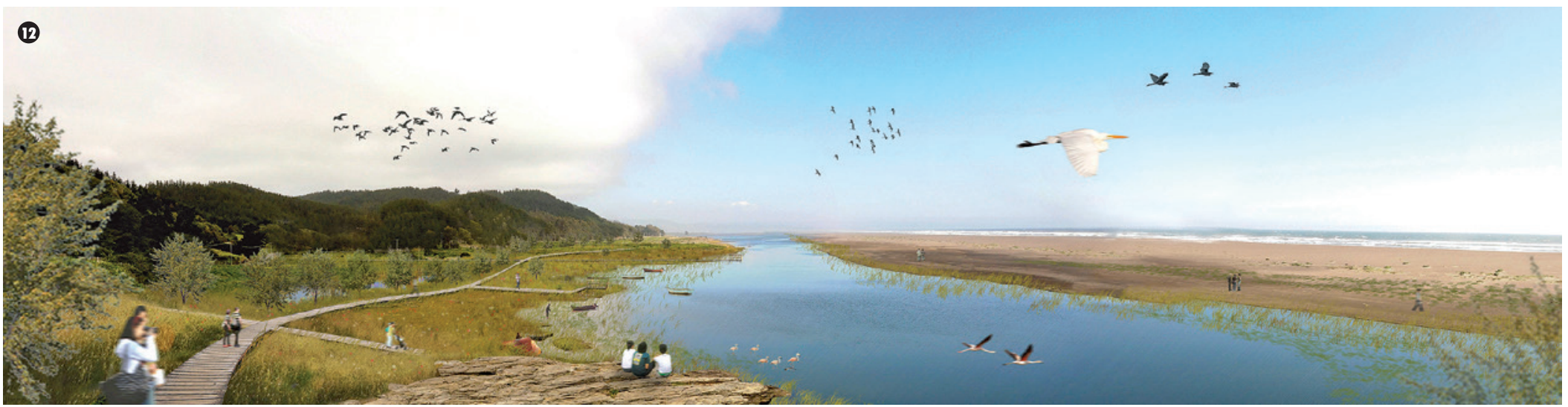

(3)

Corte Esquemático de Programa y Texturas

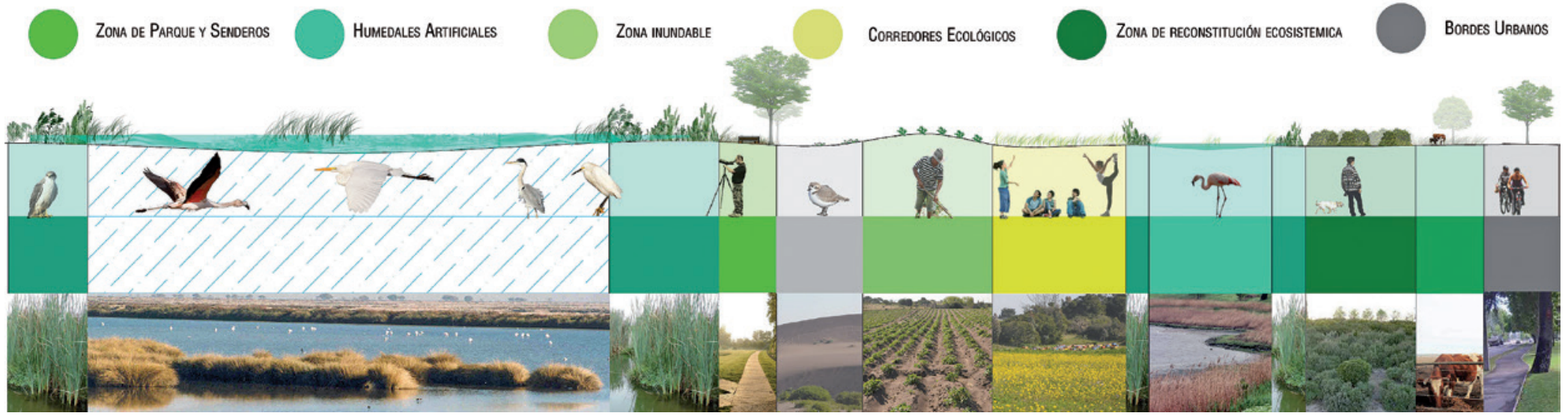

El traspaso antrópico es un bypass elevado, puentes peatonales que permiten la circulación entre ambos costados de la carretera, hoy en día solo hay un puente peatonal a lo largo de toda la ruta desde Curicó a la costa, lo que evidencia la fragmentación que produce la ruta en el paisaje y en la circulación y las pocas medidas y soluciones que se han dado al respecto.

\section{CONEXIONES LADERAS DEL RÍO}

Circuito peatonal que acompaña los hitos en el paisaje diseñados a través de parques inundable o parques esponjas, permitiendo una conexión amable entre ambos bordes del río, potenciados por un programa sostenible de áreas verdes para la comunidad, la rehabilitación ecológica y el paisaje. Se determinan puntos de vistas privilegiados para la observación y contemplación, tanto en el circuito (conformado por puentes colgantes y paseos de borde río) como en los parques inundables.

\section{INCORPORACIÓN DE VEGETACIÓN AUTÓCTONA}

En el plan se establece la liberación de forestación hasta la cota 100 msnm, produciendo un buffer de protección en los faldeos de la Cordillera de la Costa, en donde se introduce nueva vegetación autóctona, para la rehabilitación de los suelos y ecosistemas. Se diseña a partir de información cartográfica de pendientes y exposición solar, asociado a las unidades vegetales que se dan en los ambientes proporcionados por estas variantes (ambientes húmedos, sombríos, luminosos, pantanosos, rocosos, quebradas, etc.). Estas unidades vegetales están determinadas en el libro Sinopsis BIOCLIMÁtICA Y VEGetACIONAL DE CHILE de Federico Lubert y Patricio Pliscoff (2006), donde se describen detalladamente las especies autóctonas del territorio, sus características, dinámicas, distribución y condiciones ambientales para su propagación. 
14. Cortes Santuario de la Naturaleza Humedal La Pesca.

\section{ZONA BUFFER HUMEDAL}

Zona de protección en los faldeos de la Cordillera de la Costa, que dan al borde del Humedal, se propone recuperar principalmente la función protectora del suelo y agua que proporciona el bosque aledaño al humedal, a través de una rehabilitación ambiental que nos acerque parcialmente a la estructura, composición y funcionalidad del ecosistema original. Hoy en día la plantación de pino llega hasta el borde directo del humedal, afectando drásticamente su configuración, sobre todo en los momentos de tala, pues queda el suelo a ras, generando un alto nivel de escurrimiento, arrastrando tóxicos, sedimentos y un sinfín de componentes hacia las aguas del humedal.

\section{PARQUES INUNDABLES O ESPONJAS - \\ Áreas verdes en torno al agua}

Se propone un parque que reconstruya la condición natural de humedal volviendo a su esencia, a través de un lenguaje plasmado por el agua: pantanos, pequeñas charcas de aguas, humedales en diversos tamaños acompañados de la vegetación propia de estos ecosistemas. La estructura azul (agua) será entonces lo que determina las actividades, dirige la circulación y determina espacios de contemplación del parque. La nueva imagen del humedal refuerza la identidad del lugar reconstruyendo lo destruido por el hombre o la misma naturaleza (27F), reforzando la resiliencia tanto física como emocional del lugar, generando una capacidad de adaptación más moldeable a los fenómenos del entorno, siendo capaz de absorber, contener y mitigar las posibles crecidas del río/humedal o los efectos de un tsunami. Además, de promover nuevas oportunidades culturales, recreacionales, ecológicas, históricas, y económicas.

Cortes esc. 1:250 Santuario de La Naturaleza Humedal La Pesca
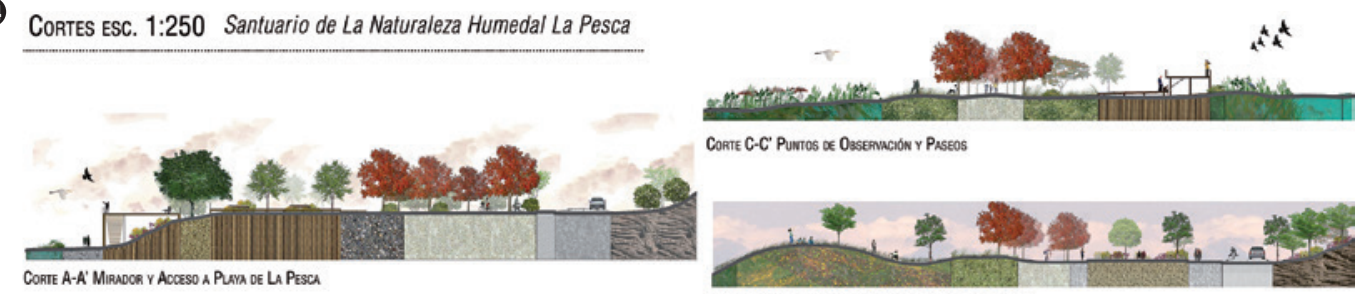

CoRTE C-C' Purros of Oasennación Y Paseos
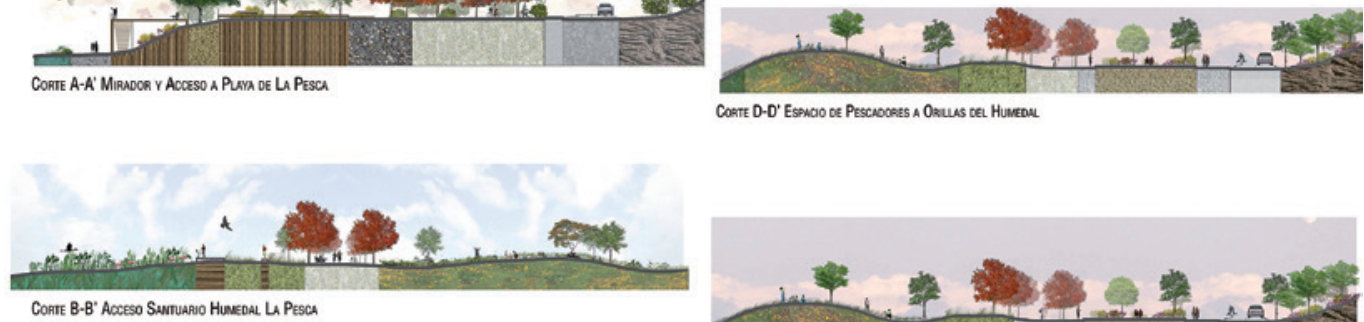

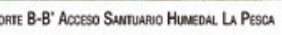

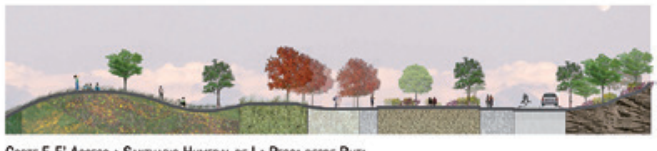

Comit E-E' Acceso a Sunnuario Humeon be LA Pesch oesse Ruta

\section{Linea de Flora Propuesta}

\section{SANTUARIO DE LA NATURALEZA HUMEDAL DE LA PESCA}

Espacio de contemplación que rescata la imagen colectiva de habitantes de La Pesca. El humedal vuelve a tener una connotación de contemplación y de centro configurador del paisaje cultural.

\section{BIBLIOGRAFÍA}

Carson, R. (1959). The Edge of the Sea. New York: The New American Library.

Magnaghi, A. (2003). Le projet local. Liège: Editions Mardaga.

Ministre d'État, minister de l'Écologie, de l'Énergie, du Developpment durable et de la Mer. A I'interface entre terre et mer: La Gestion du trait de Cote. Francia.
Lassus, B. (Editor) (1992). Hypothése pour une toisieme nature.Seminario dirigido por Bernard Lassus en el Palais du Luxembourg. Londres: Coracle Pres.

Poo Astudillo, A. (2013). Caracterización y Rehabilitación de Microcuencas Receptoras de Aves Migratorias Estudio de caso del humedal costero de Pullao, Isla Grande de Chiloé. (Tesis de Grado Carrera de Agrónomía). Pontificia Universidad Católica de Chile.

Gastó, J. (1980). Ecología: el hombre y la transformación de la naturaleza. Santiago: Editorial Universitaria

Dramstad W., Olson, J., Forman, R. (1996). Landscape ecology Principles in Landscape architecture and Land-use planning. Washington: Island Press.

Rossetti, F. (2009). Arquitectura del Paisaje en Chile: Hacia un Quehacer Contemporáneo. Santiago: Ocho Libros. 